\title{
Um caminho para educação permanente sobre o "fazer sanitário": a pesquisa qualitativa como conteúdo essencial na graduação em Saúde Coletiva
}

\author{
Edvânia Maria da Silva, Nathalie Alves Agripino, Leonardo Carnut
}

\begin{abstract}
Resumo
Segundo as Diretrizes Curriculares Nacionais (DCN) para as graduações em Saúde Coletiva, o bacharel precisa dominar os dispositivos pedagógicos para o desenvolvimento e reinvenção permanente dos saberes em saúde. Para que essa prática não se torne espontaneísta, baseada no senso comum e com baixa capacidade resistir à crítica, é necessário que o egresso produza um conhecimento sistemático de sua práxis. Logo, a pesquisa qualitativa pode ser compreendida como um conteúdo essencial nas graduações de saúde coletiva para que se proporcionem os caminhos nos quais a ,atividade educativa de si ${ }^{\text {ee }}$ deva ocorrer em virtude dos desafios encontrados na gerência dos serviços. Assim, objetivou-se identificar a percepção discente sobre as atividades práticas da disciplina de pesquisa qualitativa como forma de educação permanente em uma graduação em saúde coletiva. Tratou-se de uma pesquisa-ação, qualiquantitativa para investigação de percepção de uma realidade de trabalho. O cenário pedagógico foi a disciplina de "Metodologia Qualitativa" ministrada no $3^{\circ}$ período da graduação em Saúde Coletiva da Universidade de Pernambuco (UPE) tendo 13 estudantes como partícipes. Cada grupo de 3 estudantes foi lotado em uma Secretaria de Saúde da região metropolitana do Recife para vivenciar seus cotidianos e identificar potenciais problemas da prática para transformá-los em uma pergunta de pesquisa qualitativa. Cada estudante criou um projeto e o operacionalizou até onde fosse possível. Ao término da atividade prática, realizou-se uma entrevista não-estruturada com os estudantes sobre suas vivências. Analisou-se o material coletado através da técnica de Análise de Conteúdo Clássica, do tipo análise frequencial em comparação com a Seção II (Educação em Saúde) das DCN para os cursos de graduação em Saúde Coletiva. Das 43 ideias centrais que emergiram dos discursos dos estudantes obteve-se as seguintes categorias: 25,5\% (11) "Facilidades, acolhida e informações sobre a política de saúde"; 9,3\% (4) "Acontecimentos imprevistos"; 9,3\% (4) "Colocar em prática as teorias"; 6,9\% (3) "A visão social ampliada"; 6,9\% (3) "Crescer como acadêmico e ampliar a perspectiva"; 6,9\% (3) "Prática de pesquisa bastante limitada"; 6,9\% (3) "Criticas embasadas"; 6,9\% (3) "Serviços de saúde não estão bem articuladas"; 6,9\% (3) "Difícil processo de recolhimento de dados e informações". Segundo o que preconiza as DCN, os discursos congregam os sentidos disposto no Art 20. Inciso V: “Aprender interprofissionalmente, com base na reflexão sobre a própria prática e pela troca de saberes com profissionais da área da saúde e outras áreas do conhecimento, para a reorientação contínua dos fazeres profissionais", demonstrando o quanto os estudantes percebem esta prática como um ato de educação permanente. Segundo os achados, percebeu-se que a prática com a metodologia qualitativa parece ser uma forma de despertar nos estudantes o olhar para educação permanente. Neste estudo, a pesquisa qualitativa ampliou seus horizontes e os trouxe para uma aproximação maior com a realidade em sua totalidade. Mesmo o acolhimento e acesso as informações lhes sendo facilitadas, ainda há dificuldades para adentrar nos serviços pela sensação de ameaça que gerou nos profissionais quando os estudantes utilizam a pesquisa qualitativa para conhecer seus cotidianos em profundidade.
\end{abstract}

Descritores: Educação permanente; Sistema Único de Saúde; Prática Profissional. 